\title{
Crime Mapping in Gujrat, Pakistan using GIS
}

\author{
Syeda Ambreen Zahra ${ }^{1}$
}

\begin{abstract}
:
In previous years, crime has turned into a broad-spectrum term in Pakistan. Street crime in Pakistan is in the high range. This needs a measurable research on crime mapping. Research about crime with its spatial and temporal distribution is important because data about crime Events is one of the most necessary need to Defends against crime [19]. Crime mapping is figure out how crimes are spread evenly over the zone. GIS plays an effective role in mapping of crime. This paper puts on the diverse utilities of GIS to Identify the hot, low crime area and safe area of Gujrat, Pakistan in addition to encourage the advancement of investigation and safety strategy for policing using GIS. This Research using GIS present better investigation for crime mapping in Gujrat, Pakistan so by using GIS in police department can be successfully applied on all police stations for better safety. GIS is technological gadgets which normally improve policing process as it simplifies the cognitive metrics and relationships between spatial localities. Studies reveal that GIS can holistically be integrated with crime investigating systems of police. This indicates that GIS is feasible, adoptable and adaptable tool in crime Deducting systems. This study aims to find out generic crime activity patterns of Gujrat using applications of GIS in crime patrolling and reduction activities. This study also aims to ensure that GIS can improve crime prediction and proactive measures for crime control in Gujrat. It will not only highlight the hot spots of crime.
\end{abstract}

Keywords: Crime mapping, Spatial, GIS, Hotspot Spatial Temporal analysis, Crime Forecasts, Hotspot Mapping, Positional Errors, Predictive Ability, Temporal Information

\section{Introduction}

Theories reveal that crime show that the threat of crime raises with the metropolis and societal exchange. Increase in population of towns is directly proportional to crime rate it means crime rate increase with increase in population in an area. New towns are under construction to facilitate growing population, but existing town and localities are under immense pressure of dense population. The density of population of any area is directly connected with the facilities available in that area. Main or old cities are victims of dense or extra dense population and people due to typical mind set are reluctant to move to new localities. The Extra density of population in cities has created many social and economic problems and crime is one of them. (Gupta, Rajitha, et al, 2012).

GIS applications have been proven extraordinary partner to plot crime styles. It has practically pinpointed the impacts of crime in social, economic and other contexts. Police

${ }^{1}$ Computer Science and Information Technology, University of Lahore, Gujrat, Pakistan

Corresponding Author: msituol@gmail.com 
services have preferred using and applying GIS applications rather that old mapping pins. GIS is technological gadgets which normally improve policing process as it simplifies the cognitive metrics and relationships between spatial localities. Studies reveal that GIS can holistically be integrated with crime investigating systems of police. This indicates that GIS is feasible, adoptable and adaptable tool in crime Deducting systems. This study aims to find out generic crime activity patterns using applications of GIS in crime patrolling and reduction activities. This study also aims to ensure that GIS can improve crime prediction and proactive measures for crime control. It will not only highlight the hot spots of crime.

Therefore, any crime control system for Pakistan will be more beneficial if it is integrated with GIS crime control applications. GIS brings into use software applications and crime database to fetch, measure and analyze the facts about criminal activities. So GIS applications for Gujrat from geographical and exorcism analogical view. A GIS uses the base map to investigate and observe the mapping of crimes localities by adapting virtual base map. Initially the crime database is populated by getting information from the City Police Liaison Committee (CPLC). To digitalized the excessive decision of satellite statistics that will be employed on overlays of bottom rape. Cutting-Edge GIS technology assists in collecting spatial and temporal scopes of a crime regarding the place of crime. GIS based produced maps are given a deep analysis of crime by removing hassle areas. It hot spots the output of all the map activities and extract a variety of relationships of spatial element. (T. Balogan et al 2016). GIS applications have been proving extraordinary partner to plot crime styles. It has practically pinpointed the impacts of crime in social, economic and other contexts. Police services have preferred using and applying GIS applications rather that old mapping pins. GIS is technological gadgets which normally improve policing process as it simplifies the cognitive metrics and relationships between spatial localities. Studies reveal that GIS can holistically be integrated with crime investigating systems of police. This indicates that GIS is feasible, adoptable and adaptable tool in crime eradicating systems. This study aims to find out generic crime activity patterns using applications of GIS in crime patrolling and reduction activities. This study also aims to ensure that GIS can improve crime prediction and proactive measures for crime control. It will not only highlight the hot spots of crime, but identification of peak hours of criminal activities. In first section literature review is discussed and define different way of mapping in past. in next section defined proposed methodology for crime mapping next limitation of Research is explained and in last section conclusion and future work is define

\section{Literature Review}

GIS started to become part of crime patrolling in 1970s. Its major aim is to measure the spatial modules in the cartographic paradigm because conventional paper-based mapping was no longer possible due to increasing economic growth, urbanization and crime rate. Popular GIS turned into the Geographic Information System and it was intended to organize statistics in a natural way of Canada (1965). As suggested with the aid of Longley Good child et al (2005), a near modern approach was adopted by the census Bureau by USA to measure the behavior of a population which could be helpful in eradication of criminal activities form society. (M. Adevijk et al 2014)

GIS was implemented in the army and then its applications were brought into a Civilian GIS in the U.S and intelligence imagery software of the Nineteen Sixties (Shamsi, 2005) was started to measure crime ration for different spatial localities. Zero Now GIS has been identified by means of many types of research numerous topics were mentioned by means of the use of this era like spatial, temporal modeling, segregation and classification of facts to manipulate the large data set. MacEachren et al. Introduced the map animation and multivariate demonstration applications for information with the aid of 
concentrating the time series by way of the usage of fitness, surroundings, and demographic information. United States environmental guard organization also exercises in GIS surroundings to correlate it with scientific fashions if you want to make or produce 3 -d visualized maps. GIS also used a database gadget. They mapped crime rate and its relationship with new immigrants and their impact on the social life of permanent residents and economy.

This research was prolonged to a long duration of five decades. They formulated the analysis of crime mapping for the first half of the nineteenth century. Research conducted in 1979 by The Ecological Technique by Stanley Baldwin, established relationship chart and suggested a detailed distribution of crime map along with special points and localities from where criminals lived and appeared in crime. It was a valuable research by Shaw \& McKay which different parameters for analysis and detect crimes. Morris (1957) focused towards the relationship of the vicinity and regular crime regions where criminal's mindsets were used to live during the period of1950s and 1960s. It has molded the attitude of criminology as major components of criminology had started to be measured and analyzed by the crime patrolling department. In early 1970s, trading and economic parameters were carried forward as major attributes to detect and prevent criminology. As discussed above, the environment and weather conditions were also giving advantage to criminal mind set therefore ti were included as variables to analysis criminology and it was named as Environmental criminology. It played an important role in crime prevention. O. Newman (1972) in his book "Defensible Space" reveals that detection of unlawful in any locality could also prove helpful in prevention of crime. It was a proactive approach which could prove a handy approach to detect a crime from an unlawful gathering of getting together.

It was a sociological angle to prevent crime. Another major angle to detect and prevent criminology an area or spatial locality, it was named as geographical criminology. Environmental criminologist prepared patterns of regular crimes in some areas and movement of people in spatial localities to find out the relationship between crimes and movement of people. Gujrat is considered as the commercial hub of Punjab province and social position and affordability of its citizens is more than reasonable. This is an old city and it has its special history related to The Great Alexander and the River Chenab. It is a city of 16 Lac heads. It has two major problems: crime and care. Criminals are getting the benefit of large population residing in the congested place. There are many localities where not only visitors' even residents think themselves unsafe and insecure in terms of life and valuables. Violence and street crime have become the norm of these areas and writ of law is negligible in absence of security personals. Gujrat is not only economically strong city; it is politically also very active. Political gangs often support different plundering and looting gangs. This city has been measured with about $128 \%$ prolonged sectarian and political violence. Kidnapping and rape are also top list crimes which are supported by different groups in the city. (Persistence,2012)

\section{A. Global Distribution of Crime}

Criminological examine becoming a nicer preferred device for a competitive crime. Due to its more capability of GIS can without problems recognize hassle regions, whilst showing them in a manner that makes an easily understandable map using visual means. Geographic Information Science (GIS) makes use of replicated maps and geography as an interface for integrating annul having access to large portions of the area primarily based records. The GIS allows police personnel to plot successfully for an emergency answer, determine mitigation priorities and to take a look at ancient activities, in forecast destiny activities.

While within the various elements of Pakistan there may be a mountaineering trench of crime is delivering into being. Although Low- 
crimes societies like Islamabad and Multan are functioned lofty amongst road crime rates, other international country, i.e. Japan was also suffering an upward push in crime. Pakistan had a higher murder fee from 19802000, permitting. To. 2000 determine the rate of homicides consistent with 100.000 human beings changed into still superior to all international localities; the murder rate is also very high in South Africa as compared to other countries in the continent. Graph of rape cases is also increasing in European states. But by means of 2000, Canada took the lead in lowest rape cases registered due to implementation of GIS with crime patrolling. Robbery has been on a sound decline in Pakistan over two decades.

According to the 2000 ranking, Portugal, England, Wales and Spain have extra pronounced robberies than US countries. Germany stands at first in low robbery crimes. Italian and French localities along with Middle Eastern states, is most of the most serif us assets crime, at the same time as its far decrease in the United States today than it became in 1980. As of 2000, America had decreased housebreaking charges than Finland, Australia, Denmark, England, Wales and Canada.

\section{B. Significance of the Study}

Crime control related research regarding Gujrat is highly valuable for all law enforcement and crime control agencies to detect and prevent crime and aid in coping with crimes extra meaningfully and effectively. This could without a doubt assist Gujrat's citizens to stay in Gujrat with concord and peace. The set pursuits of this study are supportive for the position of police sources appropriate, in addition, to assist out in recognizing the various elements which can be chargeable for the high crime charged in the study region. This GIS and CRIMINOLOGYBASED research will deliver, the delivery to various strategies and rules for supervisory the crime. GIS programs are used everywhere globally to incorporate crime detection and prevention strategies. The scarcity of police resources in terms of human and physical resources is under stress due to frequent upward thrust in crime.

\section{Proposed Methodology}

\section{A. Study Area}

Gujrat is district of Punjab province in Pakistan. Gujrat is an ancient district located between two famous rivers, the Jhelum and Chenab. It is bounded on the northeast by Mirpur, on the northwest by the River Jhelum which splits it from Jhelum District.

\section{B. Map of Gujrat}

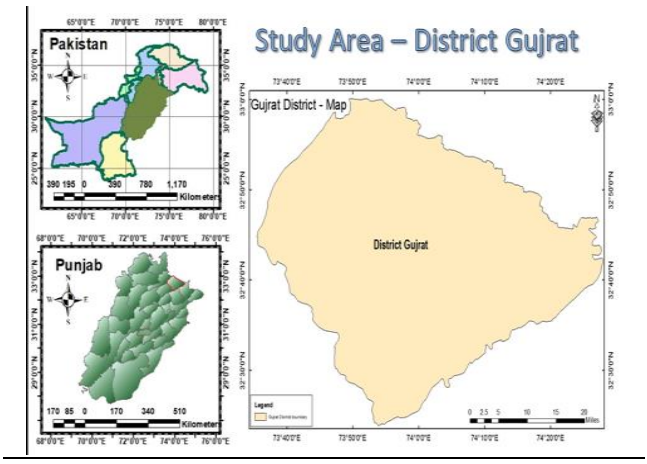

Fig 1. Study Area-Map of Gujrat District

\section{Data Used in Study}

First of all, we got approval letter from university for collecting crime data of police stations to complete our research work. After that we got 23 police station names with personal number for crime data collection. We personally visit every police station with advocate Syed irtza Haider Sharazi as a legal advisor and demand for crime data, but they denied for giving us the data and said crime data is always secret we can't give you in hard form and then we request, kindly mark crime data with us on a google earth map for completion of our research work so that some police station mark data with us on a google earth map and also some police station give 
us data in excel sheets, Google Earth ArcGIS. These two tools have different features Google earth is one of the most common applications used for locating places on the earth's surface. ArcGIS on the other hand, is used to map out locations on the earth's surface and then carry out various analyses on the selected place on the earth's surface using a variety of tools available in the program.

\section{Methodology Architecture}

The following diagram shows the methodology steps flow. In the very $1^{\text {st }}$ step, we prepared the crime dataset including area boundary, number of police stations, marking crime data from police stations and converting KML to ArcGIS and applying grid on Gujrat district including different police stations. In the $2^{\text {nd }}$ step, we performed GIS Analysis by joining spatial crime data with grid and then conversion of grid to raster and the classification of crime into 5 classes. In $3^{\text {rd }}$ step, we obtained results in categorical form of safe zone, high crime, middle level crime and low-level crime. And in the last step we presented the the obtained results in the form of crime map. In experimental study section, we explained every single step of proposed methodology.

\section{Experimental Study}

In the data preparation mark the Gujrat district boundary on the Google map after that divided in tehsil and mark police station of Gujrat on the district Gujrat map areas. With the help of police we mark crime points on the map and we covert Google earth file of crime data Gujrat into ArcGIS map format And applied Grid on Gujrat area $1 \mathrm{Sqkm}$ by $1 \mathrm{SqKm}$ on district Gujrat area for counting Crime ratio in 1 grid In GIS analysis applied to spatially join Crime With Grid for a clear representation of Data And After that Convert Grid into raster because Grid Store Boundary into points, line, polygon and Raster (Vector) store data in an aerial photograph, a satellite image. And Classify Crime into Five classes to showing high alert area and low crime alert areas and so on.

In Result obtain area shows crime Distribution on safe zone, low crime, medium crime, and High Crime.In final data presentation crime map of Gujrat district is prepared

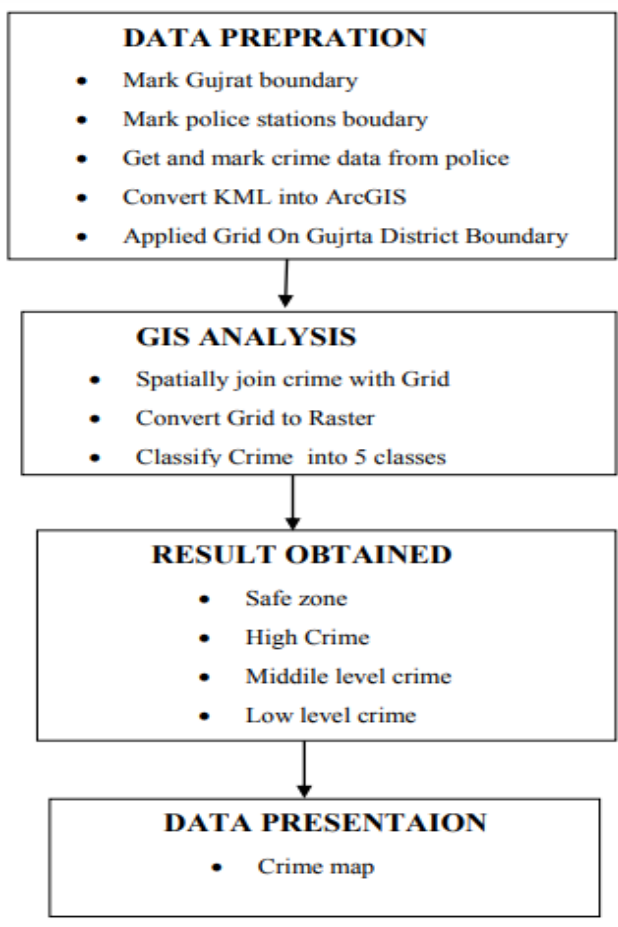

Fig 2. Architecture Diagram

\section{Limitation}

Even though this research final crime map is very useful to the police, but it does not fully cover crimes of Gujarat because of their safety and security issues. Some of the cons that come with crime maps are that sometimes they can have weighted anecdotal information. Some crime mark in police station. Some crimes are not reported. This can sometimes result in crime mapping having a bias on historical problems as opposed to emergent patterns. Therefore, deployment errors can easily occur with the Gujarat police departments. 


\section{Gujrat Police Station}

List of Police Stations District Gujrat

\begin{tabular}{|c|c|c|c|c|c|}
\hline \multirow{2}{*}{ Sr. } & City Name & Tehsil Name & Police Station Name & \multicolumn{2}{|c|}{ Location } \\
\cline { 5 - 6 } & & Latitude & Longitude \\
\hline 1 & Gujrat & Gujrat & Daulat Nagar Police Station & 32.749272 & 74.070668 \\
\hline 2 & Gujrat & Gujrat & Jalapur Jattan Police Station & 32.640191 & 74.208335 \\
\hline 3 & Gujrat & Gujrat & Sadar Police Station Gujrat & 32.569375 & 74.099828 \\
\hline 4 & Gujrat & Gujrat & Lorry Ada Police Station & 32.565545 & 74.078068 \\
\hline 5 & Gujrat & Gujrat & Police Station "A" Division & 32.570272 & 74.074064 \\
\hline 6 & Gujrat & Gujrat & Khawajgan Police Station & 32.576395 & 74.078756 \\
\hline 7 & Gujrat & Gujrat & Motorway Police Station & 32.541336 & 74.004236 \\
\hline 8 & Gujrat & Gujrat & Kunjab Police Station & 32.523992 & 73.976479 \\
\hline 9 & Gujrat & Gujrat & Mangowal Police Station & 32.494986 & 73.891864 \\
\hline 10 & Gujrat & Gujrat & Shadiwal Police Station & 32.512452 & 74.035456 \\
\hline 11 & Gujrat & Gujrat & Civil Line Police Station & 32.587171 & 74.076468 \\
\hline 12 & Gujrat & Gujrat & Shaheen Police Choki & 32.559865 & 74.046552 \\
\hline 13 & Gujrat & Gujrat & Karinwala Police Station & 32.749238 & 74.279148 \\
\hline 14 & Gujrat & Gujrat & Purana Tanda Police Station & 32.702193 & 74.369416 \\
\hline 15 & Gujrat & Kharian & Kharian Cantt Police Station & 32.804591 & 73.882252 \\
\hline 16 & Gujrat & Kharian & Kharian Police Station & 32.815325 & 73.861223 \\
\hline 17 & Gujrat & Kharian & Kakrali Police Station & 32.840309 & 74.063518 \\
\hline 18 & Gujrat & Kharian & Guliana Police Station & 32.811953 & 73.969853 \\
\hline 19 & Gujrat & Kharian & Dinga Police Station & 32.643775 & 73.721246 \\
\hline 20 & Gujrat & Sarai Alamghir & Sarai Alamgir Police Station & 32.898516 & 73.757683 \\
\hline 21 & Gujrat & Sarai Alamghir & Bulani Police Station & 32.92486 & 73.931981 \\
\hline 22 & Gujrat & Sarai Alamghir & Goteriala Police Station & 32.931069 & 74.01683 \\
\hline 23 & & & & & \\
\hline & & & & & \\
\hline
\end{tabular}

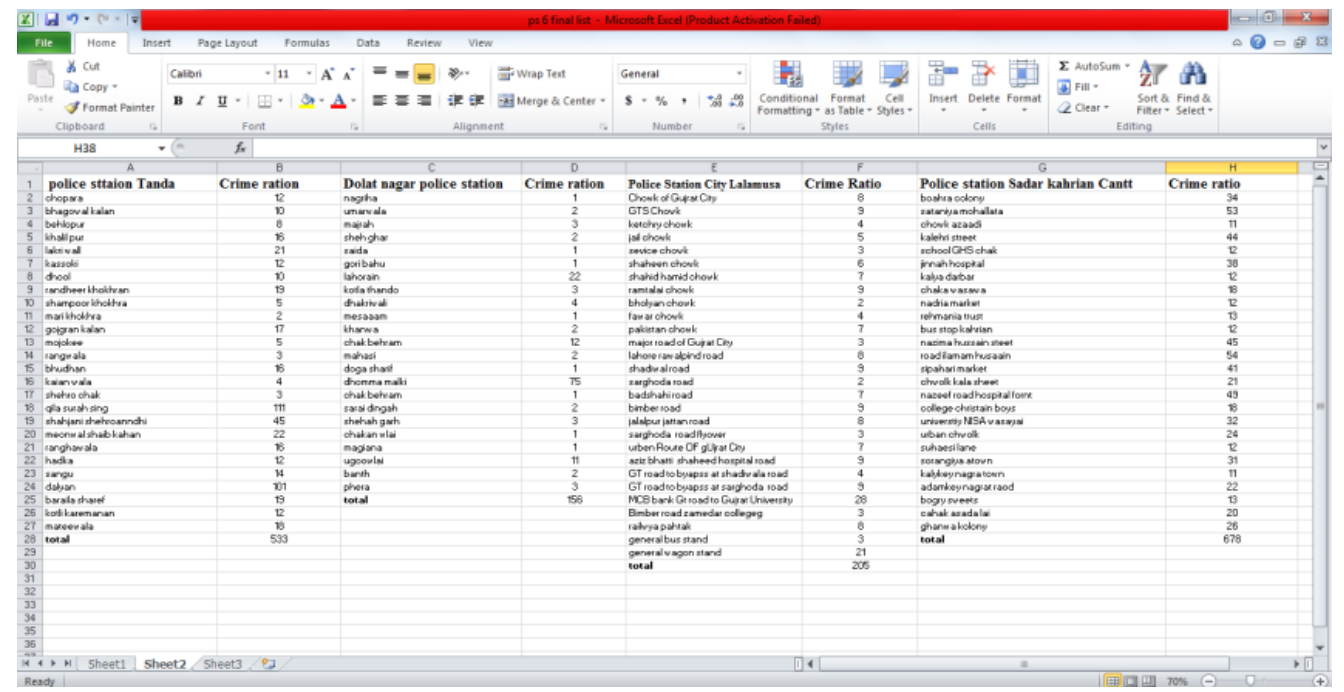

Fig.3: Crime Collection 


\section{Data Marking}

\section{Step 1:}

Map of District Gujrat map on Google earth

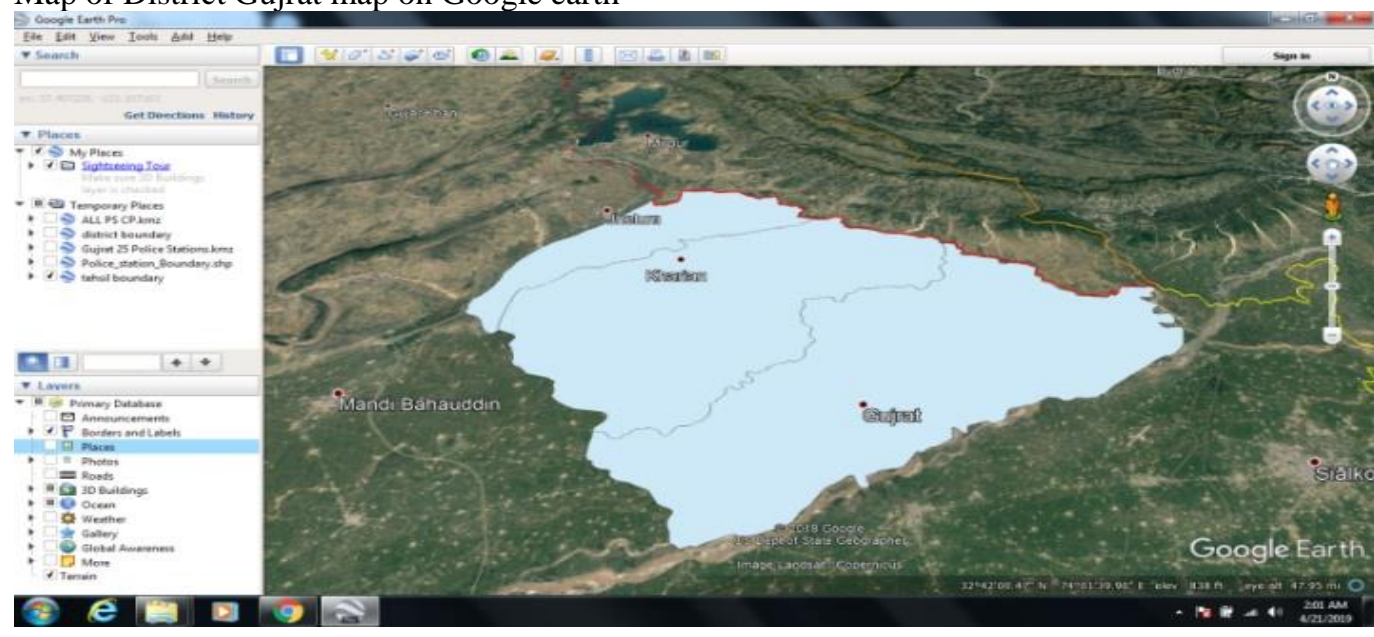

Fig 4: Gujrat map on Google earth

Step 2:

Showing police station boundary on a Google earth map

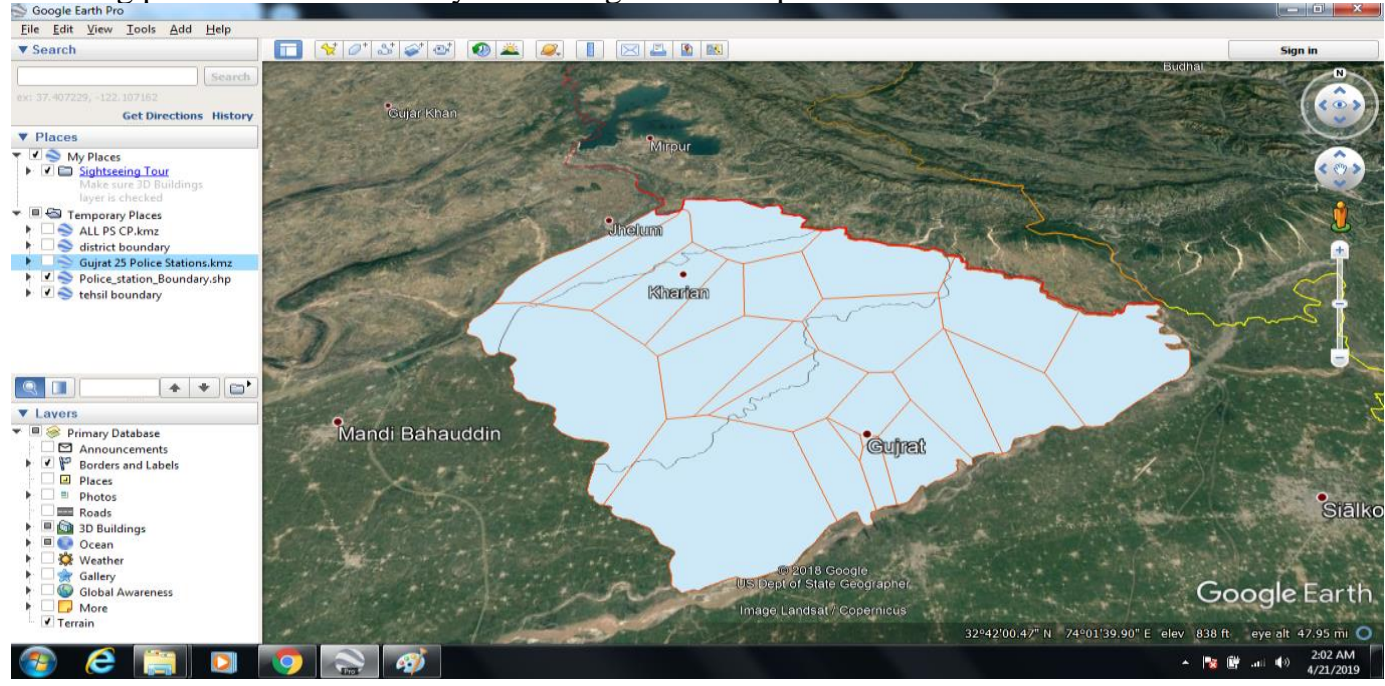

Fig 5: Police station boundary on a Google earth map 
Step 3:

Marking police station on a Google earth map

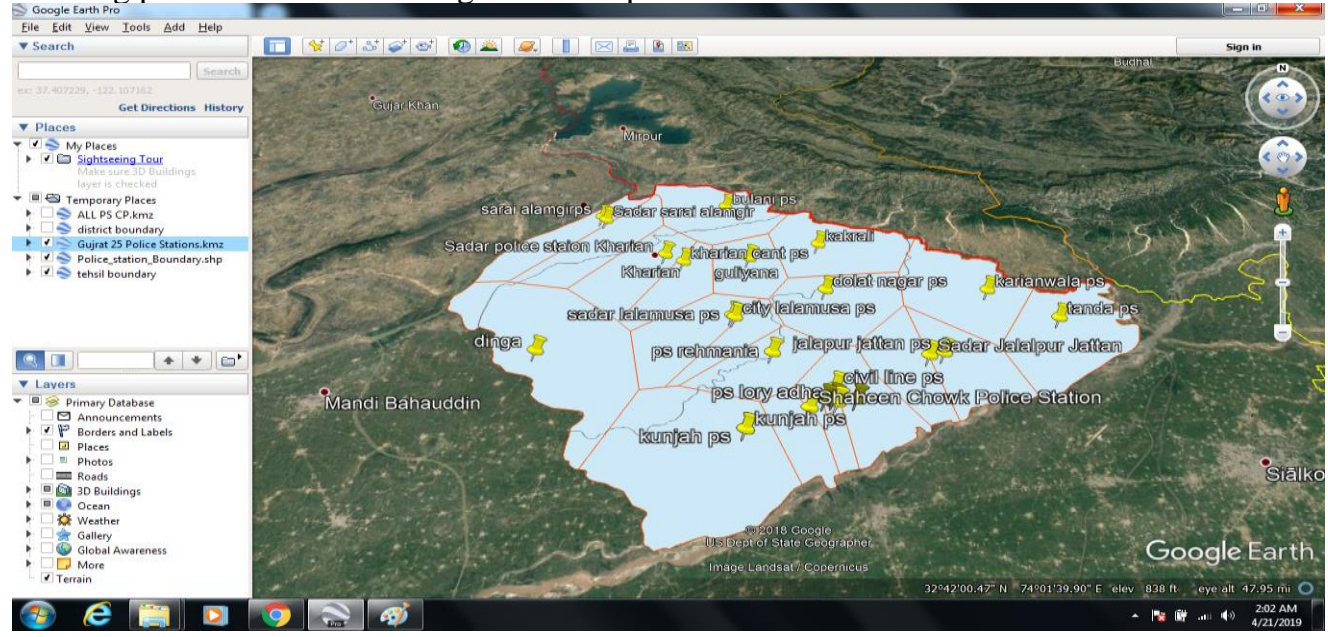

Fig 6: Police stations on a google earth map

Step 4:

Marking crime points of All Police Stations on Google earth.

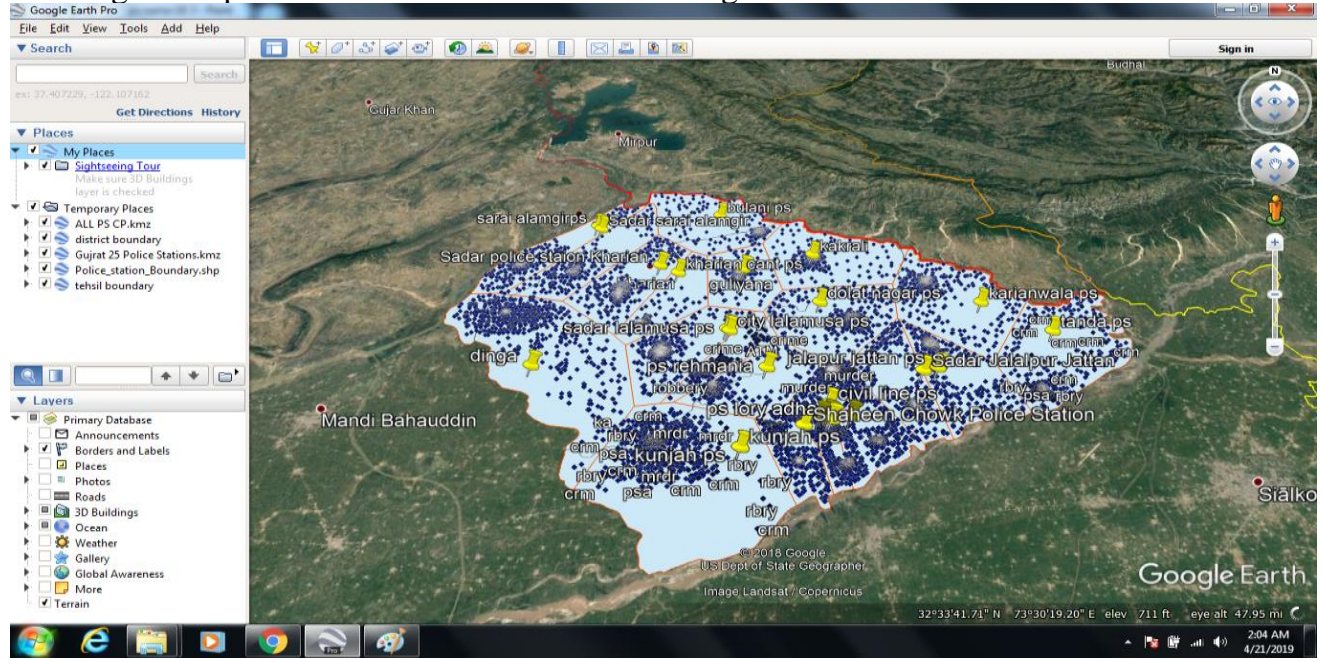

Fig 7: All police Stations on google earth 


\section{Step 5:}

Converting google earth KML file for ArcGIS.

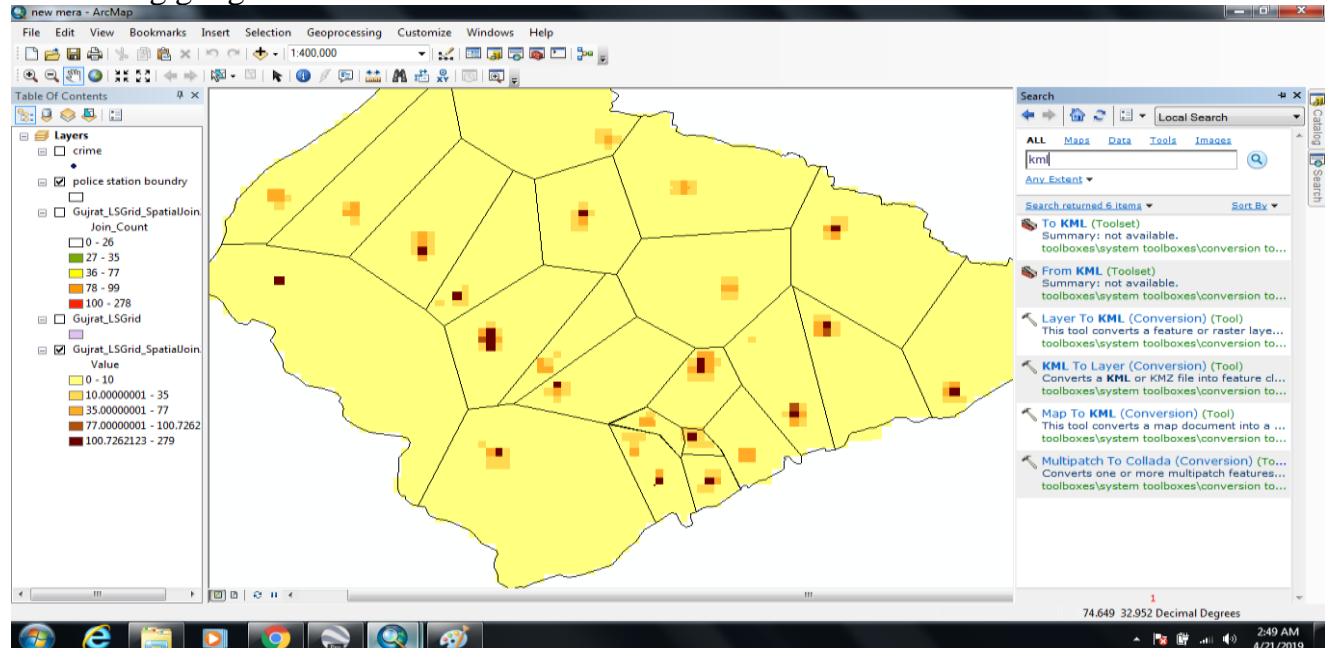

Fig 8: Converting google earth KML file for ArcGIS

Step 6:

After conversion into ArcGIS format for results.

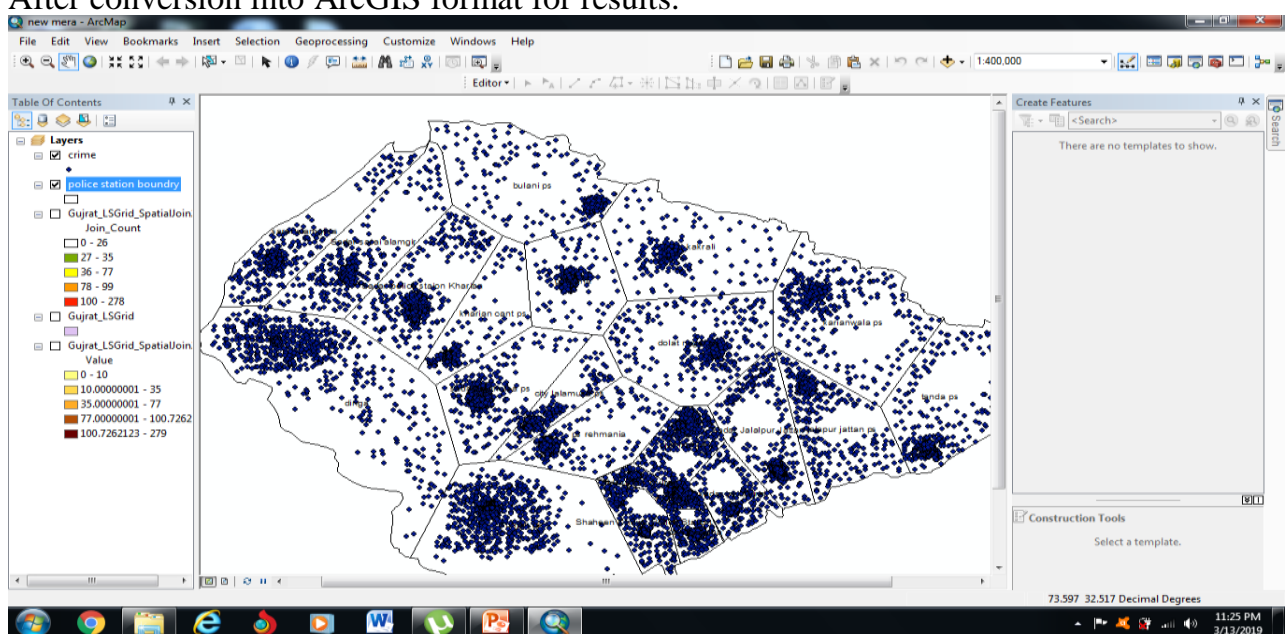

Fig 9: Point Conversion into ArcGIS format 
Applied Grid 1skm by $1 \mathrm{sqKm}$ on the Gujrat District Area

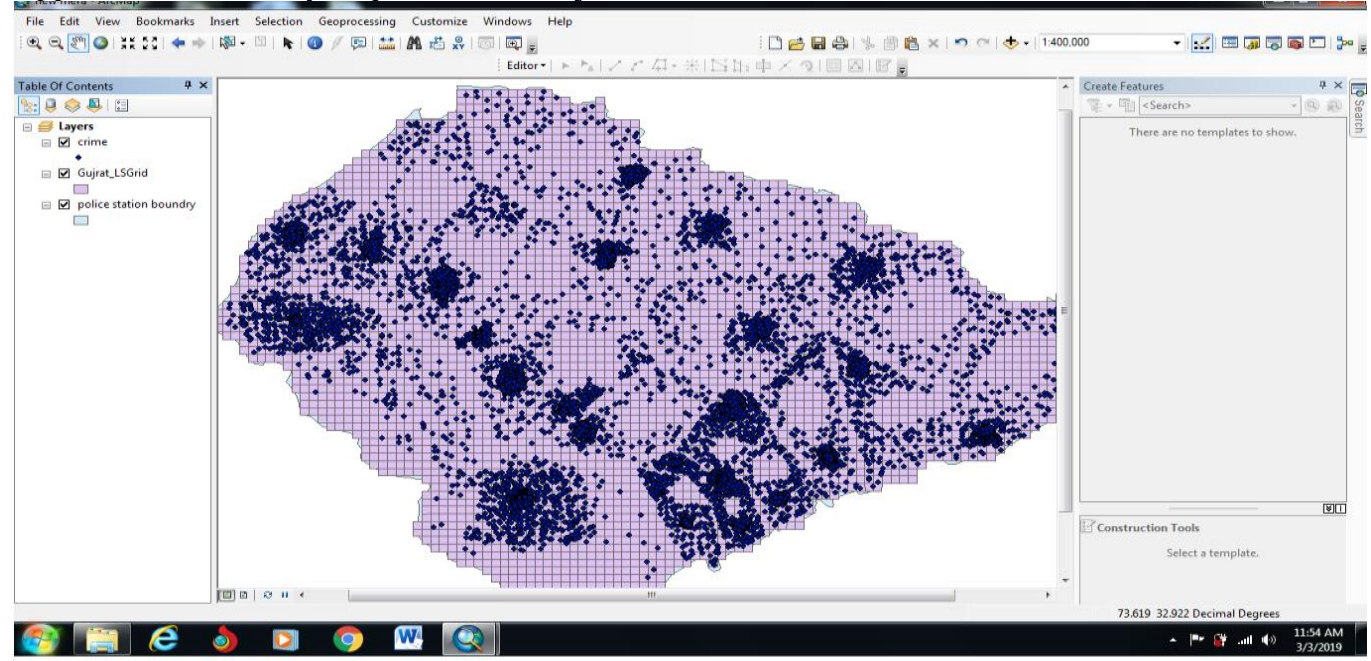

Fig 10: Applied Grid 1skm by 1sqKm

Step 8:

Applied crimes spatially join with grid.

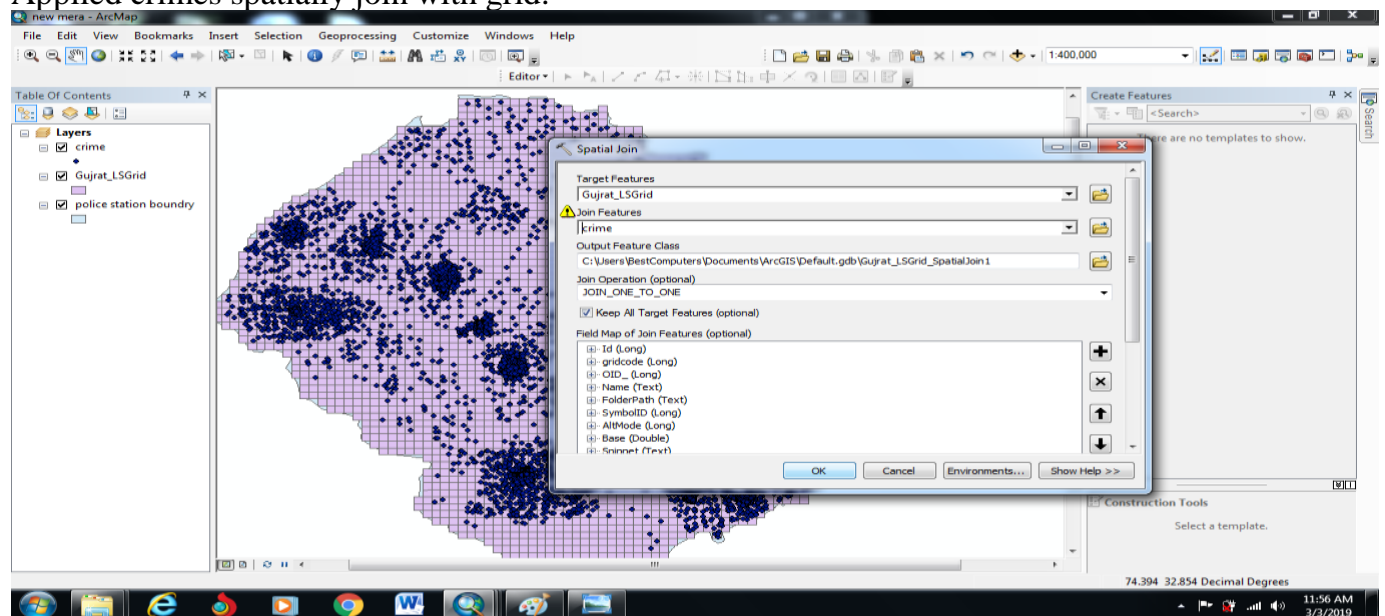

Fig 11: Crimes spatially join with grid 
Step 9:

Showing high crime areas result.

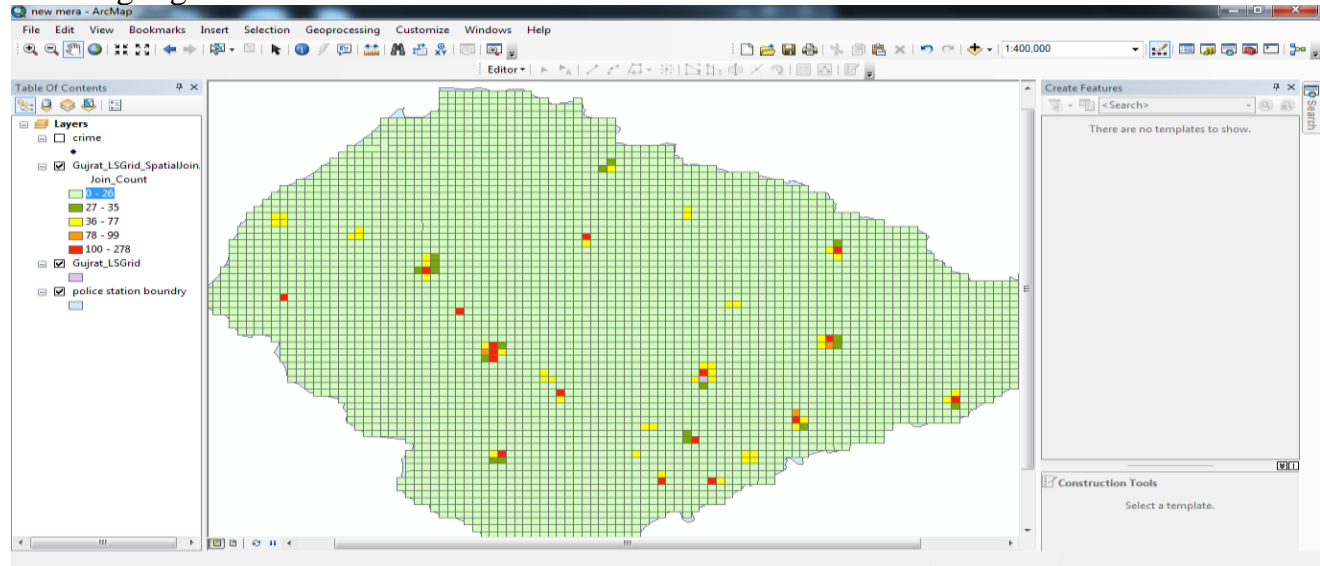

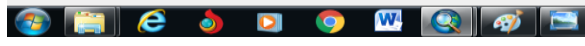

Fig 12: High Crime Areas

Step 10:

Conversion of Grid to Raster.

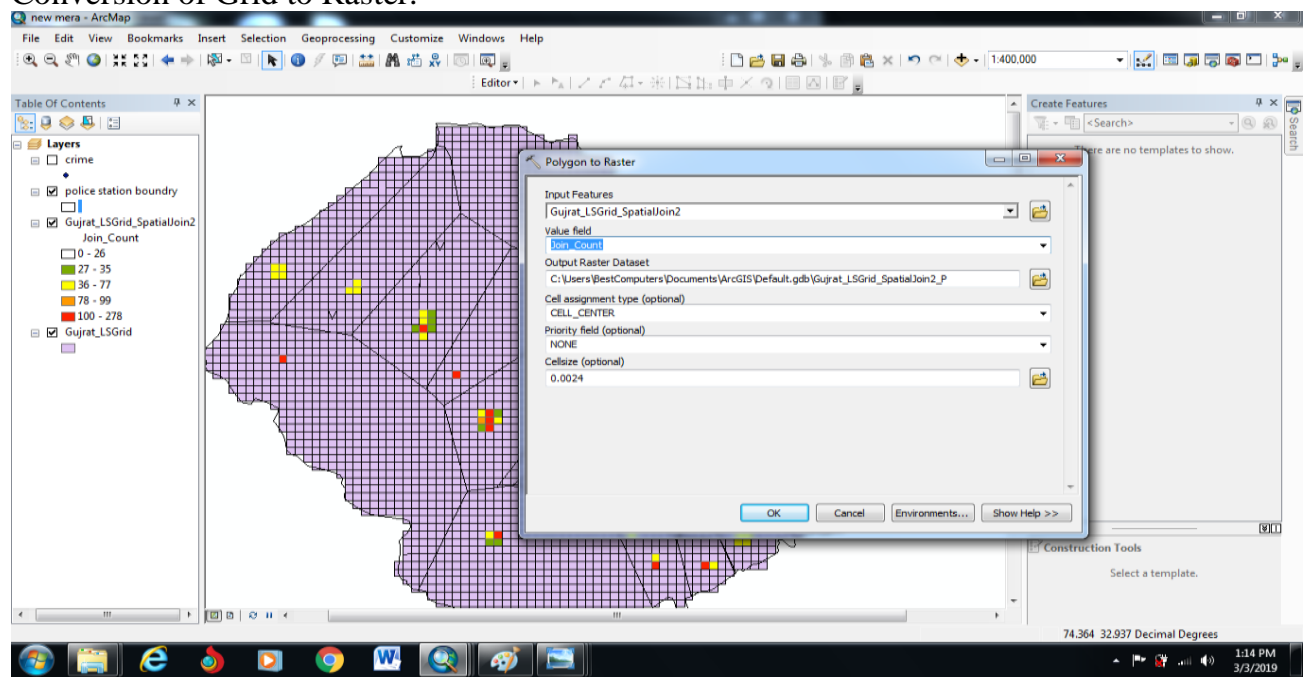

Fig 13: Conversion of Grid to Raster 
Step 11:

Setting crimes classification into 5 classes with crime range we are showing crime range in figure but we can change into percentage.

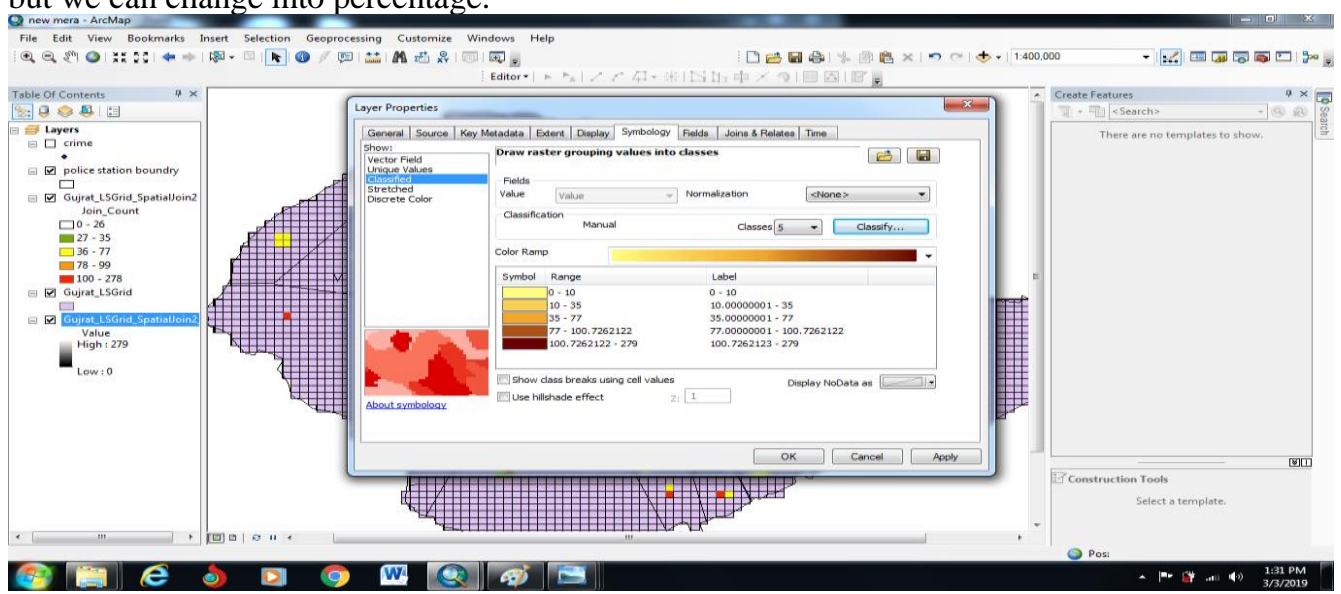

Fig 14: classes with crime range

Step 12:

Result Shows Crime Distribution (Safe Zone, Low Crime, Medium Crime, High Crime \& Dangerous Area)

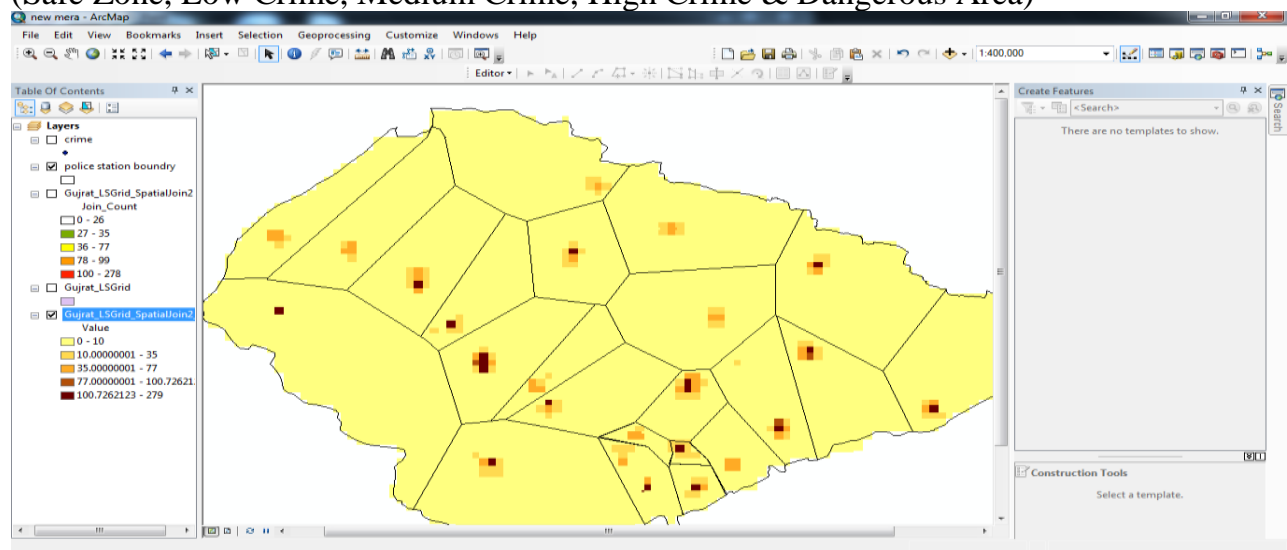

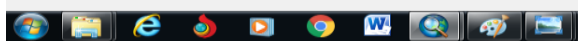

Fig 15: Crime Zones 
Step 13:

Showing overall District Gujrat Crime result of all police stations.

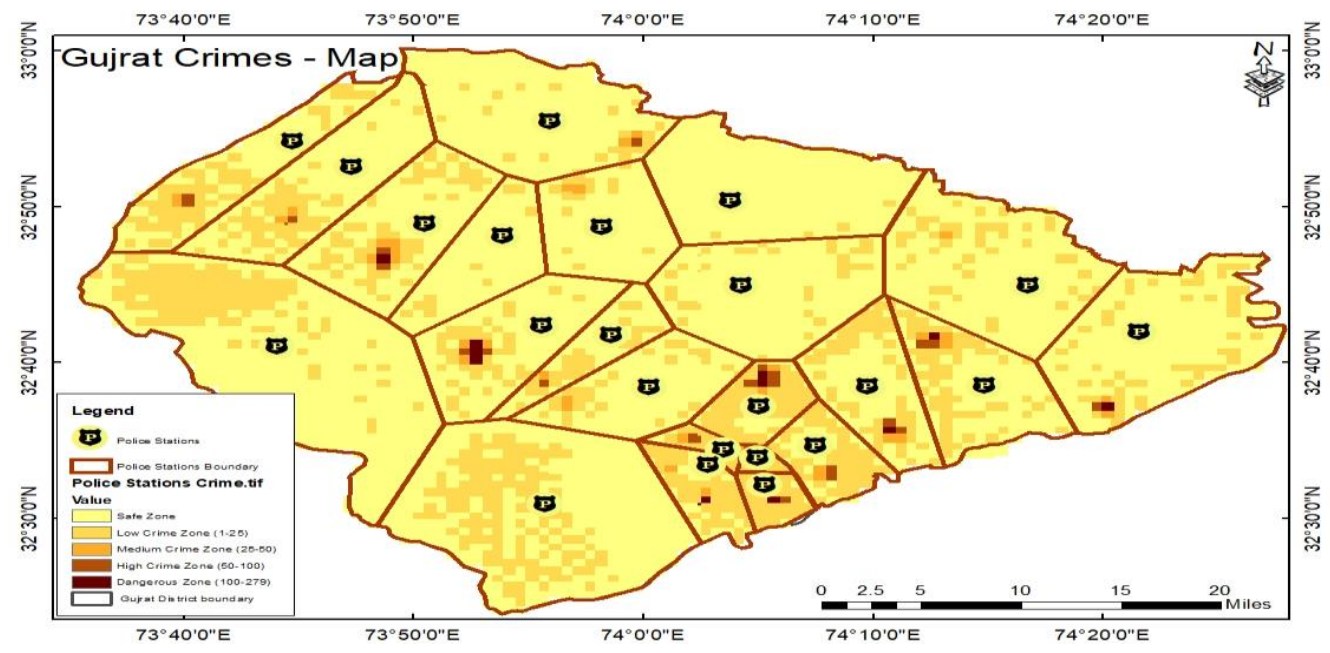

Fig 16: All Police Stations Results

\section{Conclusion and Future Work}

It is concluded from this learning that crime is considerate and deadly hassles in Gujarat. Diverse criminals are approximately stated from every corner of Gujrat at a dangerous charge, but criminology of this area exists in all the times and among all heads of the region to vicinity basis. The criminal entities have a superb dating with the attached landscape, social and economic structure that's located in this study so which will recognize the crime. The Study indicates that function of geography facilitates in simplifying the crime scenes. Positive space with respect to geographical elements and their relationship with criminology enables in information gathering in the form of the crime pattern called crime patterns in GIS. Gujrat is an important metropolitan in the region of Punjab so it has different geographical, economic, social, cultural, religious and political dimensions which are all taken an important part of each crime control and crime prevention system.

This study presents one of the most vital positions the first GIS based Jurisdiction map of Gujrat police stations. A novel and advance surveillance versioning of Gujrat crime patrolling which is connected with via GPS (Global Positioning System). Our GPS with secondary source-based survey showed in this study that GIS primarily based map of police stations of Gujrat is also developed which is protecting relevant information of police stations. It is the first time in Gujrat that GPS with secondary survey is confirmed for acquiring the locations of criminal activities. Until this study, no such action was determined to be taken in Gujrat while such frameworks are employed and incorporated to detect and prevent major sort of crimes.

Whatever techniques make sense for you, concerning and analyzing GIS into crime mapping and protection is two times a hit preference as your development, your personal career must make substantial additions for social freedom and order. Think of it as advantages for one battle. GIS is used to measure and analyze crime rate with respect to spatial and temporal localities are different in geographical areas with respect to timings. These entities alter with the passage of time. The area, time zone, law, criminals, target or victim are elements of GIS based crime 
patrolling system which are observed in geographical space. The GIS based strategy suggests law to interrupt crook to dedicate and target no longer homogeneous everywhere on the surface as a way to admire the change in location of criminal mindset. GIS apprehends the character of criminology using surrounding geography, demography and socioeconomic structure and these methods will take from the roots In-spite of that it will become a stable shaft. It is better to compare

\section{REFERENCES}

[1] T.F. Balogun et al., "Crime Mapping in Nigeria using GIS" , Journal of Geographic Information System, vol. 6, no. 5, pp. 453- 466, 2014.

[2] S.M. Ansari and Dr. K.V. Kale, "Methods of Crime Analysis using GIS", International Journal of Scientific and Engineering Research, vol. 5, no. 12, pp. 1330- 1336, 2014.

[3] U.S. Usman, "The Role of Geographic Information System (GIS) in Effective Control of Terrorism in Nigeria", International Journal of Economics, Commerce and Management, vol. 3, no. 4, pp. 1- 9, 2015.

[4] F. Fajemirokun et al., "A GIS Approach to Crime Mapping and Management in Nigeria: A Case Study of Victoria Island Lagos", Nigeria.

[5] N. Levine, "Crime Mapping and the Crimestat Program", Wiley Online Library. [Online]. Available: http://onlinelibrary.wiley.com/doi/10.11 11/j.0016 7363.2005.00673.x/full. [Accessed: 22- Nov- 2016].

[6] A. Ahmed \& R. Saliha, "spatiotemporal pattern of crime using GIS approach in Dala L.G.A. Kano state, Nigeria", American Journal of Engineering Research, vol. 2, no. 3, 2013.

[7] G.O. Igbaekemen \& S.U. Umar, "A Purview into the historical Development of Terrorism in Nigeria", Journal of Developing country Studies, vol. 4, no. 14, 2014.

[8] O. James, "GIS and Crime Management in Nigeria", International Journal of Sociology, Management and Security Studies, Maiden Edition, Kano, Nigeria, 2013

[9] F. Onu, "Corrupt Practices in Nigeria Society", A Search For Causes and past and present variations of crimes in Gujrat that are fantastically coping of crimes in Gujrat.

- Temporal analysis of Data

- Collect data with categories and types

- $\quad$ Every crime must be open in GIS form

Remedies. IJMSSS, Kano State, Nigeria, vol. 1, no. 1, 2014

[10] J. Shekwo, "Juvenile Delinquency in Mararaba, Karu L.G.A. of Nasarawa State, Nigeria", International Journal of Sociology, Management \& Security Studies, Maiden Edition, Kano, Nigeria, 2013

[11] S.A. Yelwa \& Y. Bello, "Complimenting GIS and Cluster Analysis in Assessing Property Crime in Katsina State, Nigeria", American International Journal of Contemporary Research, Vol. 2, no. 7, 2012

[12] S. Pires"crime mapping and analyses news",International Journal of Science and Technology, vol. 4, no. 5, pp. 1-30 , 2012.

[13] M.A.P chamikara.,"GIS in crime analysis", International Journal of Science and Technology, vol. 3, no. 6, pp. 3, 2014.

[14] J. Bueermann.,"Crime analysis",Journal of Environment and Earth Science, vol. 2, no. 3, pp. 1-6, 2012.

[15] M.brokmaan et al.,"Crime Mapping and Analysis in the Dansoman Police Subdivision", Journal of Environment and Earth Science, vol. 4, no. 3, pp. 111,2014

[16] C.D.J beaty.,"GIS for Crime Analysis, Law Enforcement, GIS and Public Safety", Journal of Environment and Earth Science, vol. 4, no. 3, pp. 117,2012.

[17] T.Fransic et al.,"Crime Mapping in Nigeria",scrip.org.[Online].Available: http://www.scirp.org/journal/PaperInfor mation.aspx ?PaperID=50296. [Accessed: 20- Nov- 2016].

[18] j.corso et al.," Toward Predictive Crime Analysis via Social Media, Big Data, and GIS", Journal of Environment and Earth Science, vol. 2, no. 3, pp. 1-6, 2015. 
[19] S.Muhammad et al.," Mapping and Analysis of Crime in Aurangabad City using GIS", IOSR Journal of Computer Engineering (IOSR-JCE), vol. 2, no. 4, pp. 67-76, 2014.

[20] F.Wang.,"Why Police and Policing need GIS",Journal of Environment and Earth Science, vol. 2, no. 4, pp. 67-76, 2012.

[21] T.Balogan et al.," Crime Mapping in Nigeria Using GIS",Journal of Geographic Information System, vol.6, no. 4, pp. 453-466, 2014.

[22] J. H. Davis and J. R. Cogdell, "Crime in GIS," Elect. Eng. Res. Lab., Univ. Texas, Austin, Tech. Memo. NGL-006-69-3, Nov. 15, 1987.

[23] R. E. Haskell and C. T. Case, "Hotspot in Crime mapping," USAF Cambridge Res. Labs., Cambridge, MA, Rep. ARCRL66-234 (II), 1994, vol. 2.

[24] P. Diament and W. L. Lupatkin,"GIS in Crime Mapping,” Dept. Elect. Eng., New York, Sci. Rep. 85, Aug. 1991

[25] Crime with GIS, 3rd ed., Western Electric Co.,Winston-Salem, NC, 2010, pp. 44-60.

[26] GIS in Crime mapping., 1st ed.,Spencer Chainey, Jerry Ratcliffe., 2010,pp.1-421.

[27] "Hartsfield-Jackson Atlanta International Airport," [Online]. Available: Http://Www.Esri.Com/Software/Arcgis/ Arcgisonline. Accessed: Nov. 25, 2016.

[28] R. Gipta, Et Al," Application of GIS in Crime Analysis: A Gateway to Safe City", 14th International Conference and Exhibition on Geospatial Information Technology and Applications.Vol.1, No.6, 2014.

[29] Ferreria, Joao, "GIS For Crime Analysis: Geography For Predictive Models", Electronic Journal Information Systems Evolution. Vol.1, no.15 2012.

[30] [Online]. Available. Http://Link.Springer.Com/Chapter/10.10 07\%2f978 3-319-27793-6_1, Accessed: Dec. 1, 2016.

[31] Courso, Leroy, "Towards Predictive Crime Analysis via Social Media, Big Data, And GIS", Conference, Vol.1, no.6, 2015.

[32] W. Fan, Y. Chen, "Design And Study On Police", Intelligence Analysis System Based On GIS. Vol.1 No. 4, 2011.

[33] [Online]. Available. Www.Slideshare.Net/Osokop/Fundame ntalsofcrimemapping1, Accessed: Dec. $1,2016$.
[34] J.M. Caplan, "Mapping the spatial influence of crime correlates: A comparison of operationalization schemes and implications for crime analysis and criminal justice practice. Cityscape", Vol. 13, no. 3, pp. $57-83,2011$.

[35] J. M. Caplan et al., Risk Terrain Modeling Diagnostics Utility User Manual (Version 1.0). Newark, NJ: Rutgers Center on Public Security. Retrieved March 1, 2014 from http://rutgerscps.org/software

[36] M. Averdijk \& H. Elffers, "The discrepancy between survey - based victim accounts and police reports revisited", International Review of Victimology, Vol. 18, no. 2, pp. 91 - 107, 2012

[37] Katcrime, "Rising wave of criminality in Katsina". [Online]. Available: http://www.nigeriaa2z.com/2012/04/08/ rising-waveof-criminality-in-katsina/. [Accessed: 24- Dec- 2016].

[38] L. W. Kennedy et al., "A Primer on the Spatial Dynamics of Crime Emergence and Persistence." (2012), Retrieved March 1, 2014 from http://www.rutgerscps.org/PrimerOnCri meBook.html.

[39] J.E. Gyong, "Criminal Victimization and the

Reporting of Crime in Kaduna State: Towards

Integrating the Victim of Crime into Criminological

Discourse", Current Research Journal of Social

Sciences, Vol. 2, no. 5, pp. 288 - 295, 2010

[40] C. Dempsey, "GIS 101: Learn About GIS GIS Lounge", GIS Lounge. [Online]. Available:

https://www.gislounge.com/gisessentials/. [Accessed: 12- Dec- 2016].

[41] "Applications of GIS in Crime Mapping - ESDS Official Knowledgebase", ESDS Official Knowledgebase. [Online]. Available: https://www.esds.co.in/kb/applicationsof-gis-in-crime-mapping/. [Accessed: 16- Nov- 2016].

[42] A. Hiropoulos and J. Porter, "Visualising property crime in Gauteng: Applying GIS to crime pattern theory", South African Crime Quarterly, no. 47, 2016.

[43] "Crime Mapping (continued) - How GIS Is Used in Law Enforcement", Ncjrs.gov. [Online].
Available:

\footnotetext{
Sukkur IBA Journal of Computing and Mathematical Science - SJCMS | Vol. 3 No. 2 July - December 2019 ( ) Sukkur IBA University
} 
https://www.ncjrs.gov/ovc_archives/rep orts/geoinfosys $2003 / \mathrm{cm} 3 \mathrm{~b} . \mathrm{html}$.

[Accessed: 26- Nov- 2016].

[44] "The Impact of GIS Technology - Nov 30 , 2016", Journals.sagepub.com.

[Online]. Available: http://journals.sagepub.com/doi/abs/10.1 068/b250681. [Accessed: 20- Dec2016]. [45] S. jews"essays Journal of Science and Technology, vol. 3, no. 4, pp. 1-12, 2012.

[46] M.luciman.,"using hotspot in GIS", International Journal of Science and Technology, vol. 2, no. 5, pp. 5 , 2014.

[47] J.lexopiya.," crime act control using GIS",Journal of Environment and Earth Science, vol. 1, no. 2, pp. 1-3, 2012.

[48] S.ruceli et al.," Crime Mapping and Analysis", Journal of Environment and Earth Science, vol. 2, no. 2, pp. 111,2012 .

[49] C.Axeaty.,"GIS and Public Safety", Journal of Environment and Earth Science, vol. 3, no. 2, pp. 1-10,2013.

[50] I.crispo et al.," Big Data,and GIS", Journal of Environment and Earth Science, vol. 3, no. 4, pp. 1-4, 2014.

[51] S.Frezonet al.," Mapping and Analysis of crime", IOSR Journal of Computer Engineering (IOSR-JCE), vol. 1, no. 3, pp. $61-70,2012$.

[52] P.Wrex.," Policing need GIS",Journal of Environment and Earth Science, vol. 1, no.3, pp. 61-65, 2013.

[53] Y.Manishia.,"Crime effects", International Journal of Science and Technology, vol. 1, no. 2, pp.3, 2012. 